\title{
Usos do Glossário do Risco em Revistas: Contrastando "Tempo" e "Públicos"
}

\section{Uses of the Risk Glossary in Magazines: Contrasting "Time" and "Public"}

\author{
Mary Jane P. Spink**a, Adriana Bernardes Pereira ${ }^{a, b}$, Lívia Barbosa Burin ${ }^{a}$, \\ Mariana Adão da Silva ${ }^{a} \&$ Priscila da Rocha Diodato ${ }^{a}$ \\ ${ }^{a}$ Pontifícia Universidade Católica de São Paulo, São Paulo, Brasil \\ ${ }^{b}$ Universidade Católica de Goiás, Goiânia, Brasil
}

\begin{abstract}
Resumo
Este ar tigo visa contribuir para a compreensão das maneiras de falar de risco na mídia, apoiando-se no referencial teórico da Psicologia Social discursiva. Duas estratégias complementares de investigação foram utilizadas: análise diacrônica de amostra de revista de interesse geral (210 exemplares da Veja) e sincrônica de revistas destinadas a públicos variados (101 revistas). A análise da Veja focalizou as temáticas das matérias e anos de sua publicação. Para a amostra sincrônica foram priorizadas as temáticas das revistas de modo a entender o endereçamento a públicos distintos. A análise "no tempo" sugere que os glossários do risco-perigo e riscoprobabilidade já estão consolidados e seu uso traz ressonâncias dos contextos históricos em que essas tradições tomaram forma. No enquadre do risco-aventura, vimos surgir novos vocábulos para referir-se às emoções dos esportes radicais ou posicionar aqueles que optam por correr risco. Esses usos da linguagem do risco são mais bem apreendidos no fluxo da comunicação em que o público tem cara: as revistas segmentadas.

Palavras-chave: Linguagem dos riscos; práticas discursivas; mídia; governamentalidade.
\end{abstract}

\begin{abstract}
This paper is a contribution to the understanding of risk-talk in the media from a theoretical perspective of discursive Social Psychology. Two complementary strategies were used: diachronic analysis of a sample of a magazine of general interest (210 issues of Veja) and synchronic analysis of magazines directed to various types of people (101 magazines). For Veja, the analysis focused on article themes and date of publication. For the synchronic sample, priority was given to how risk is presented to different kinds of public. The analysis "over time" suggests that risk as danger and risk as probability glossaries are already well established and their use is a resonance of the historic contexts in which this tradition took shape. New repertoire emerges in the tradition of risk as adventure to refer to emotions associated with radical sports or to people who choose to take risks. This use of language is best seen in the flow of communication in which the public has a face, as in magazines directed to specific segments of the public.

Keywords: risk language; discursive practices; media; governamentality.
\end{abstract}

Trabalhamos, neste texto, com a noção de risco tal como utilizada nas práticas discursivas cotidianas. Não se trata, portanto, de acompanhar os interstícios e debates sobre risco como conceito, mas de analisar, a partir da perspectiva discursiva, seu uso de senso comum e os glossários aos quais "risco" passou a estar associado; o que se convencionou chamar de "linguagem dos riscos".

A palavra risco tornou-se de uso corrente nas línguas indo-européias por volta do século XVI, em um período em que havia se tornado factível pensar o futuro como

* Endereço para correspondência: Pontifícia Universidade Católica de São Paulo, Programa de Estudos Pós-graduados em Psicologia Social, Rua Monte Alegre, 984, São Paulo, SP, 05014-901. Tel./Fax: (11) 3670-8000. E-mail mjspink@pucsp.br

Pesquisa desenvolvida com o apoio do Conselho Nacional de Desenvolvimento Científico e Tecnológico (CNPq), Bolsa Produtividade, Processo No 522056/97-0 passível de controle. Entretanto, a formalização do risco como conceito fundamental para a gestão de coletividades é fenômeno mais tardio que se sustenta no desenvolvimento de uma tecnologia específica: o cálculo de probabilidades que possibilitou a eventual estruturação do campo da "Análise dos Riscos".

A partir de meados do século XX, a análise dos riscos assentou-se em três pilares: o cálculo do risco, a percepção do risco pelo público e a gestão dos riscos (que, mais recentemente, passou a envolver a comunicação do risco para o público). Trata-se de campo que é palco de acirrados debates que confrontam posturas objetivistas e socioculturais (Beck, 1992; Douglas, 1992; Lupton, 1999) que desembocam no consenso (pouco confortável para uns) de que a definição do que vem a ser risco está imbricada com valores e ordens morais que extrapolam a racionalidade do cálculo do risco. 
Na modernidade tardia, esse debate se deslocou da esfera dos valores para a esfera do cálculo, uma vez que os riscos contemporâneos tendem a ser imponderáveis. Porém, sejam eles calculáveis ou imponderáveis, na medida em que afetam a coletividade, são obrigatoriamente objetos de gestão pública, tanto nos micro-contextos de cada cidade, Estado, nação, como no macro-contexto da sociedade globalizada. Riscos associados à falência econômica, ao terrorismo internacional, à destruição ambiental, à contaminação por agrotóxicos, ao emprego de novas tecnologias na saúde, assim como os do cotidiano urbano precisam ser calculados, segurados e gerenciados. E, como estratégias contemporâneas de governo, necessitam entrar no circuito comunicativo como resposta ao imperativo da comunicação na gestão dos riscos. É nesta perspectiva que a reflexão sobre o estudo empírico da linguagem dos riscos assume relevância para a Psicologia Social.

Falamos sobre linguagem a partir da Psicologia Social. Como tal, não são os aspectos lingüísticos propriamente ditos, mas as possibilidades de produção de sentidos que pautam nossa conceituação de linguagem. Como suporte teórico, as posições de Mihail Bakhtin (1994, 1995) fornecem um solo conceitual valioso para a compreensão dos sentidos na vida cotidiana.

Para Bakhtin, a unidade básica da comunicação é o enunciado. Este, entretanto, não pode ser entendido isoladamente, pois "Qualquer enunciado é um elo em uma corrente formada de maneira muito complexa por outros enunciados" (1994, p. 69). Um enunciado é, simultaneamente, resultado da criatividade do ato singular (do estilo individual) e do tipo de enunciados a que pertence.

Com efeito, o indivíduo dispõe, certamente, de formas idênticas às de qualquer outro membro da comunidade, mas nenhuma forma, no entanto, isto é, nenhuma abstração pode ser transmitida a quem quer seja a não ser na concretude da relação, com todas as nuanças ou colorações sociais, psicológicas ou simplesmente afetivas pelas quais e nas quais se perfilam os sujeitos singulares. A dimensão criadora das atividades pertencentes a diferentes áreas, por um lado, em número maior ou menor conforme os indivíduos, não se inscreve numa mesma ordem de coisas. A normatividade se exprime nas combinações que o enunciado realiza, enquanto sua individualidade resul ta da livre concepção, pelo locutor, de seu projeto discursivo (Faïta, 1997, p. 171).

Essa relação dialética entre conhecimento situado e dialogicidade e o solo mais normativo em que se processa a comunicação é trabalhada por Bakhtin por meio das noções de linguagem social e gêneros de fala. Esses conceitos possibilitam a integração de propostas aparentemente irreconciliáveis: enunciados singulares produzidos por vozes singulares e tipos de enunciados produzidos por tipos de vozes.

As linguagens sociais são discursos peculiares a estratos específicos da sociedade (grupos profissionais, etários, campos de conhecimentos distintos, etc.), num determinado sistema social e numa determinada época; ou seja, não existem no vácuo. Segundo Bakhtin (1994, 1995), um locutor sempre invoca uma linguagem social ao produzir um enunciado, mas faz isso se apropriando desta e povoando-a com suas próprias intenções e estilo. Portanto, a linguagem é uma construção híbrida - um atravessamento de vozes, estilos e tipos de enunciados.

Em contraste, os gêneros de fala são caracterizados, sobretudo, por temas e situações típicas de comunicação. Bakhtin afirma que "um gênero de fala não é uma forma de linguagem, porém uma maneira típica de enunciado; assim, ao ser expresso, o gênero carrega uma tipicidade que lhe é inerente" (1994, p. 87). Isso se aplica tanto às comunicações corriqueiras do cotidiano, como às diversas formas de comunicação científica e gêneros literários. Entretanto, a tipicidade dos gêneros de fala não é estanque, pois esses são atualizados, continuamente, por meio de diferentes práticas discursivas. Segundo Bakhtin, os "enunciados e suas formas típicas, isto é, os gêneros de fala, são as correntes transmissoras (drive belts) da história da sociedade para a história da linguagem" (p. 65). A dinâmica entre as formas estáveis de enunciados e os usos singulares que deles são feitos fornece o enquadre para pensar a relação entre linguagem dos riscos, tradições discursivas e usos específicos de enunciados sobre risco.

Também é a partir da argumentação de Bakhtin de que qualquer enunciado (oral ou escrito) implica presença de interlocutores, presentes, passados e futuros, que se materializam nas noções de vozes e de endereçamento, que podemos compreender os textos escritos, incluindo aí a mídia na forma de revistas, como práticas discursivas e acatar o princípio de que toda linguagem é dialógica. Nessa perspectiva, as práticas discursivas são as maneiras pelas quais se articulam as linguagens sociais existentes e os gêneros de fala, produzindo singularidades de uso e hibridizações discursivas, como nos mostra o estudo da linguagem dos riscos.

Tomando por fundamento o conceito de linguagem social, propomos que, desde que os riscos puderam ser pensados na perspectiva da gestão, formataram-se certas constâncias discursivas que nos permitem falar da existência de uma linguagem dos riscos. Adam e van Loon referem-se a esta nos seguintes termos:

A linguagem dos riscos está tradicionalmente associada ao mundo econômico das trocas e das apólices de seguros, ao mundo médico na relação entre profissionais da saúde e seus pacientes, aos esportes radicais e às pessoas que "arriscam" suas vidas por outros. Nessas situações tradicionais de risco, as pessoas calculam o risco potencial de certas ações e tomam decisões, fazendo escolhas à luz de suas avaliações . . . A linguagem dos riscos, entretanto, é e sempre foi inescapavelmente social. A percepção de risco pressupunha uma relação particular com um futuro essencialmente desconhecido cuja probabilidade de ocorrer podia, todavia, ser calculada tomando como base freqüências passadas: uma resposta sociocultural calculada em antecipação a acontecimentos potenciais 
... Nessa perspectiva, o mundo do cálculo de riscos pressupõe diferenciações nítidas entre o que é seguro e perigoso, entre verdadeiro e falso e entre passado e futuro. (Adam \& Van Loon, 2000, p. 7).

O foco da reflexão de Adam e Van Loon (2000) é o ordenamento do risco na modernidade tardia (compreendida segundo teorizações de Beck, 1992). Sendo esses riscos mais desordenados e menos propensos ao cálculo, Adam e van Loon argumentam a favor da necessidade de mudar o gênero prevalente que articula riscos e perigos com base no cálculo para outro gênero que leve em conta os sentidos que são atribuídos ao risco em diferentes contextos. Ou seja, postulam ser necessária uma nova linguagem.

Já a nossa proposta (Spink \& Menegon, 2004), mais próxima à teoria lingüística de Bakhtin, é que jamais apagamos as vozes que falam a partir de outras linguagens sociais, por mais inadequadas que possam vir a ser. Além do mais, a linguagem dos riscos que se formata no decorrer dos séculos, desde que risco se tornou objeto de gestão, se expressa de formas diferentes, quando usada em contextos distintos, por exemplo, no âmbito das três tradições discursivas propostas por Spink (2001).

Os discursos sobre risco definem territórios lingüísticos que demarcam campos de gestão nos quais se desenvolvem maneiras específicas de falar sobre riscos. Assim, ao nos referirmos à linguagem dos riscos, embora usando o singular, não estamos propondo a existência de uma linguagem unitária. Estamos sugerindo que, no interior de cada campo de saber e fazer, se desenham formas de falar sobre riscos que lhe são específicas e que estão presas a três tradições discursivas muito distintas: a fala de sensocomum sobre perigos, a perspectiva do controle e disciplina e a perspectiva da aventura.

A primeira tradição, que antecede a emergência da palavra e, portanto, do conceito de risco, concerne as experiências de infortúnios, muitas vezes imprevisíveis, que fogem das possibilidades de cálculo. É uma tradição raramente considerada nas análises de risco, mas que certamente se faz presente nas análises discursivas sobre os modos de falar sobre risco no cotidiano.

A segunda tradição remete à perspectiva histórica dos discursos sobre risco colados à governamentalidade (no sentido usado por Foucault, 1995), ou seja, ao governo de populações e ao risco objetivado pela quantificação. Referenda, portanto, medidas coletivas destinadas a gerenciar a distribuição e o movimento de pessoas nos espaços físicos e sociais. Nessa tradição discursiva, a metáfora mais utilizada para posicionar as pessoas com relação aos riscos é estar em risco (Spink, 2000a, 2001). Todavia, legitima, também, como subproduto, os processos de disciplinarização da vida privada que se constituíram historicamente em duas etapas. A primeira está vinculada ao movimento higienista do final do século XIX e à moral da prevenção: higiene pessoal, do lar e moral. No decorrer do século $\mathrm{XX}$, por ter aumentado a expectativa de vida, em decorrência do controle de doenças infecciosas e melhorado as condições sociais, as doenças crônicas tornaram-se preocupações centrais da Saúde Pública. Progressivamente, os conhecimentos médicos passaram a definir novos padrões de controle. Nessa segunda etapa dos processos de disciplinarização, cada pessoa, mediante acesso à informação, passa a ser responsável pelo autogerenciamento de sua saúde. O estilo de vida como forma de autocontrole é a face mais famosa dessa reorganização e "É nessa esfera que vemos emergir uma das mais potentes metáforas sobre os comportamentos perante riscos: correr riscos" (Spink, 200ob, p. 163). No que se refere à prevenção, a lógica passa a ser evitar os riscos.

A terceira tradição, que aproxima os campos da Economia e dos Esportes, herda a positividade da aventura e apresenta especificidades discursivas quanto à lógica da governamentalidade. Assim, um conjunto de repertórios sobre risco que, de certa maneira, escapa à governamentalidade, exibe conotações que fazem do correr riscos uma prática necessária para alcançar determinados ganhos. Nessa perspectiva é a satisfação pessoal que passa a fundamentar a comparação entre riscos e benefícios (Renn, 1992).

Essa terceira tradição é ressignificada na modalidade das emoções radicais. Certos esportes radicais são domesticados e, até certo ponto, reintegrados à vertente da governamentalidade, posto que se apóiam em regras e equipamentos de segurança e, muitas vezes, buscam manter viva a tradição de fortalecimento de caráter. Entretanto, em oposição à aventura presa a regras ou a pressupostos higienistas, encontra-se hoje um crescente número de modalidades de aventura que procuram exacerbar a emoção, o que levou alguns teóricos do risco a incorporarem a noção de risco desejado (Machlis \& Rosa, 1990).

Cada um desses territórios lingüísticos desenvolve vocabulários específicos que constituem glossários - conjuntos de repertórios lingüísticos - que são ativados em nossos enunciados sobre risco, conforme apresentado na Figura 1.

\begin{tabular}{lll}
\hline Risco-perigo & Risco-probabilidade & Risco-aventura \\
\hline & & \\
Ameaça & Risco & Aventura \\
Perda & Aposta & Adrenalina \\
Sorte & Chance & Emoção \\
Perigo (perigoso) & Seguro (segurança) & Radical \\
Azar & Probabilidade & Extremo \\
Fortuna(do) & Prevenir (prevenção) & Desafio \\
Fatalidade & Arriscar (arriscado) & Ousadia \\
Obstáculo & & \\
Ventura & & \\
Destino & & \\
\hline
\end{tabular}

Figura 1. Os glossários do risco.

Trata-se de classificação por nós desenvolvida gradualmente. Em um primeiro momento, tomamos por base a literatura sobre o tema e a exploração dos dicionários de 
etimologia de várias línguas indo-européias. Essa primeira classificação, de caráter mais histórico, foi apresentada e discutida em texto publicado em 2001 (Spink, 2001). Em um segundo momento, foram incluídos verbetes mais contemporâneos, utilizados para falar sobre o futuro, decorrentes da pesquisa diacrônica realizada na Folha de São Paulo (Spink, Medrado \& Mello, 2002). Finalmente, com base na análise realizada na pesquisa ora relatada, pudemos acrescentar novos verbetes - especialmente aqueles relacionados ao risco-aventura - criando, assim, três dicionários específicos: risco-perigo (que inclui termos que antecedem a linguagem dos riscos propriamente dita, mas são por ela incorporados, sobretudo nos discursos do senso comum); risco-probabilidade (a linguagem dos riscos associada à probabilidade e cálculos de ocorrência) e o risco-aventura (as maneiras de falar sobre a positividade do risco).

Em certos contextos lingüísticos, esses glossários são disciplinarizados pelo gênero de fala aí predominante, como é o caso das áreas tecnológicas e na Epidemiologia, nas quais risco é conceito, e não meramente um vocabulário usado para falar de certos fenômenos sociais. Porém, na complexidade das interações cotidianas, os glossários se libertam de amarras estruturais e se tornam repertórios disponíveis para dar sentidos às nossas experiências. Essa complexidade se faz presente, por exemplo, nas comunicações midiáticas de vários tipos, em que a diversidade de autores e temas transcende as demarcações territoriais dessas tradições discursivas. Daí o interesse nas revistas que circulam entre nós.

\section{Objetivos e Procedimentos}

A pesquisa teve por objetivo contribuir para a compreensão das diferentes maneiras de falar de risco na mídia impressa. Partimos do pressuposto de que a mídia tem um papel fundamental na circulação de repertórios utilizados para a produção de sentidos no cotidiano de nossas vidas, por ser onipresente no mundo contemporâneo e por conferir uma visibilidade sem precedente aos acontecimentos (incluindo aí as novas informações e descobertas) que leva a uma reconfiguração das fronteiras entre o espaço público e privado e produz novas formas de comunicação e interação.

A pesquisa englobou duas estratégias complementares: a análise diacrônica de uma revista de interesse geral e a análise sincrônica de uma amostra de revistas destinadas a públicos variados. Na perspectiva diacrônica, interessavanos situar o uso de repertórios das três tradições discursivas em diferentes áreas temáticas, de modo a complementar as informações obtidas em pesquisa anterior realizada na Folha de S. Paulo, também em uma perspectiva temporal (Spink et al., 2002). Já Sabíamos que a linguagem dos riscos é um fenômeno recente na mídia, que surgiu timidamente nos anos pós-guerra e cresceu nos anos oitenta e noventa. Além disso, na presente pesquisa, importava-nos entender mais especificamente a emergência da tradição do risco-aventura e, para isso, optamos por usar uma única revista de informação/interesse geral para fugir das especificidades da linguagem social (Bakhtin, 1994) de revistas temáticas (de turismo, esporte, moda, etc.) ou daquelas voltadas a grupos muito específicos (revistas femininas, masculinas, infanto-juvenis ou para adolescentes).

Dentre as revistas de informação/interesse geral criadas há mais tempo (A Veja data de 1968; a Exame, de 1971 e a Isto É, de 1976) e que ainda estão em circulação (Editora Abril, 2000), elegemos a Veja. Trata-se de revista de grande circulação que existe há mais de três décadas, o que possibilita a discussão sobre como a linguagem do risco, em suas três tradições discursivas, vem sendo utilizada ao longo do tempo.

Para viabilizar a pesquisa, foi definida uma amostra ${ }^{1}$ que teve como principal critério o sorteio de seis revistas por ano, em meses e semanas intercaladas, no período de 1968 a 2003, totalizando 212 exemplares. O critério de sor teio foi o mês: o primeiro exemplar do ano inicial (1968) foi escolhido por sorteio, sendo sorteados, a seguir, um exemplar a cada dois meses de publicação. A fim de se considerar o fator sazonalidade (acontecimentos que se repetem a cada ano, como férias, Natal, etc.), o mês escolhido em um ano não foi incluído no ano seguinte. Dessa forma, procuramos garantir que todos os meses e todas as épocas do ano tivessem, pelo menos, um exemplar de revista analisado.

$\mathrm{Na}$ perspectiva sincrônica, interessava comparar o uso do glossário do risco em revistas destinadas a públicos diversos. Com esse intuito, foi definida uma segunda amostra, com base nas informações do Anuário de Mídia - Revistas do ano de 2002, levando-se em conta o modo de distribuição das revistas, as temáticas e a periodicidade de circulação.

A distribuição de revistas no Brasil é feita por meio de venda direta em bancas, por assinatura ou de forma dirigida, quando se trata de publicações gratuitas e promocionais. De modo a garantir a disponibilidade das revistas ao público geral, definimos como critério de inclusão a venda em bancas de jornal.

O Anuário (2002) utiliza 49 temáticas que foram por nós reagrupadas em 15 categorias: Informação Semanal; Interesse Geral e Atualidades; Populações Específicas (Femininas, Adolescentes, Infanto-juvenis, Masculinas); Esporte, Turismo e Meio Ambiente; Economia e Administração; Assuntos Domésticos; Automobilismo e Transportes; Arte, Cultura e Música; Engenharia, Arquitetura e Construção; Alimentos, Bebidas e Gastronomia; Eletrônica, Ótica e Mecânica; Informática e Telecomunicações; Agropecuária e Animais; Saúde e Beleza; Outros.

As revistas que constam do banco de dados circulavam em periodicidades diversas: semanais, quinzenais, mensais, bimensais, semestrais, anuais. Para fins de amostragem,

\footnotetext{
${ }^{1}$ Agradecemos à Professora Yara Castro da Pontifícia Universidade Católica de São Paulo (PUC-SP) pelo cálculo da amostra
} 
essas diversas periodicidades foram agrupadas em três categorias: até um mês, mensais, e semestrais. A amostra assim definida incluiu 210 revistas: 24 até um mês, 134 mensais e 51 semestrais.

Para a composição do acervo foi escolhido o mês de outubro por não ser excessivamente marcado por determinados eventos do calendário cultural do país (por exemplo, dezembro, por causa do Natal; janeiro e fevereiro, pelas férias de verão e carnaval). Das 210 revistas, foram localizadas e compradas 101 revistas. Foi mais fácil comprar as revistas que circulavam semanal e quinzenalmente. Note-se também que, à medida que a circulação diminuía, a dificuldade de busca aumentava. Para tentar suprir essa falta, fizemos contato com as distribuidoras; todavia a dificuldade permaneceu, quiçá como reflexo da introdução freqüente de novas publicações em um mercado aparentemente muito competitivo.

\section{Procedimentos de Análise}

A análise dos dados incorporou duas estratégias: (a) caracterização das revistas considerando sua história, proposta editorial, estrutura e dados de circulação; (b) mapeamento de todos os exemplares da amostra, buscando localizar usos da linguagem dos riscos, tendo como parâmetro o glossário do risco. Para preenchimento desta tabela, foram elaboradas categorias de conteúdos que apareciam em cada página dos exemplares analisados. Esta etapa possibilitou a elaboração de quadros quantitativos sobre o uso da linguagem dos riscos nos anos e revistas analisadas, e a inclusão de uma breve descrição dos tipos de matérias e anúncios e do público alvo potencial.

Os dados foram analisados de modo a respeitar as especificidades dos dois corpus: as 210 exemplares da Veja e as 101 revistas da amostra sincrônica. No caso da Veja, a análise focalizou as temáticas e os anos. No caso da amostra sincrônica, foram quantificadas as nomeações do glossário para cada revista e, em um segundo momento, para cada categoria de temática, para que fosse possível analisar o endereçamento a públicos distintos.

\section{Resultados}

Os resultados serão apresentados separadamente para os dois corpus de dados: a amostra de exemplares da revista Veja e amostra de revistas endereçadas a segmentos diversos de leitores.

\section{O Uso do Glossário do Risco na Revista Veja:} A Perspectiva Diacrônica

Considerando-se que a linguagem dos riscos está mais bem elaborada em certas áreas, como Saúde e Economia, as matérias localizadas foram classificadas em nove áreas temáticas. Essas áreas, até certo ponto, reproduzem as seções específicas da revista, lembrando, entretanto, que a amostra englobava 35 anos e, nesse período, ela sofreu várias reorganizações em sua estrutura. $\mathrm{Na}$ análise do uso do glossário do risco, foram utilizadas as seguintes áreas temáticas: Ambiente, Economia, Educação, Esportes; Lazer; Política; Saúde, Tecnologia e Trabalho.

$\mathrm{Na}$ temática Ambiente, incluíram-se todas as ocorrências do glossário do risco que diziam respeito a questões urbanas e rurais. Na Economia, foram classificadas matérias da seção específica da revista que leva esse nome, além de outras que se referiam a investimentos e finanças. $\mathrm{Na}$ temática Educação, além das matérias presentes na seção de mesmo nome, constaram aquelas relacionadas a escolas ou seus alunos. Em Esportes, foram incluídas as matérias que abordavam a profissionalização de modalidades esportivas. Quando essas atividades não eram realizadas em competições ou não envolviam patrocínio, foram classificadas como Lazer. A temática Lazer englobou, também, matérias que diziam respeito a entretenimento, produtos culturais (livros e filmes que faziam alusão à aventura) e atividades de turismo que utilizavam a aventura como atrativo. Em Política, foram incluídas as matérias que faziam menção à gestão governamental de questões públicas nacionais e internacionais, além de situações que envolviam representantes políticos ou seus partidos. $\mathrm{Na}$ temática Saúde, foram selecionadas as matérias que se relacionavam a doenças e sua prevenção, muitas das quais localizadas na seção de mesmo nome. Em Trabalho, foram inseridas as matérias que envolviam atividades profissionais diversas, assim como aquelas relacionadas a empregos. Os temas referentes aos avanços tecnológicos, sobretudo na telecomunicação, informática e meios de transporte aéreos, foram classificados em Tecnologia.

Encontramos 259 matérias com glossário relacionado à linguagem dos riscos: 128 com palavras associadas ao risco-probabilidade, 77 com risco-aventura e 54 com riscoperigo. A Tabela 1 mostra a distribuição dos glossários e tradições de discurso sobre risco para cada área temática. 
Tabela 1

Análise Sincrônica: Glossário do Risco por Tradição e Área Temática

\begin{tabular}{|c|c|c|c|c|c|c|c|c|c|c|c|}
\hline & lossário & Política & Lazer & Economia & Saúde & Tecnologia & Esportes & Ambiente & Trabalho & Educação & Total \\
\hline \multirow[t]{6}{*}{ Risco-perigo } & Perig* & 9 & 4 & 3 & 5 & 2 & 1 & 5 & 1 & & 30 \\
\hline & Ameaça & 7 & 1 & 2 & 1 & & & 3 & & 1 & 15 \\
\hline & Sorte & 3 & 1 & 1 & & & & & & & 5 \\
\hline & Azar & 2 & & 1 & & & & & & & 3 \\
\hline & Fatalidade & 1 & & & & & & & & & 1 \\
\hline & Total & 22 & 6 & 7 & 6 & 2 & 1 & 8 & 1 & 1 & 54 \\
\hline \multirow{6}{*}{$\begin{array}{l}\text { Risco- } \\
\text { probabilidade }\end{array}$} & Risco & 17 & 13 & 17 & 16 & 8 & 3 & 2 & 3 & 1 & 80 \\
\hline & Segur* & 9 & 6 & 3 & & 7 & 2 & 2 & 1 & 3 & 33 \\
\hline & Aposta & & 1 & 6 & 2 & 1 & & & & & 10 \\
\hline & Chance & 2 & & 1 & & & & & 1 & 4 & \\
\hline & Prevenir & & & & 1 & & & & 1 & & \\
\hline & Total & 28 & 20 & 27 & 19 & 16 & 5 & 4 & 5 & 4 & 128 \\
\hline \multirow{6}{*}{$\begin{array}{l}\text { Risco- } \\
\text { aventura }\end{array}$} & Aventura & 4 & 25 & 1 & 1 & 2 & 7 & 1 & 2 & & 43 \\
\hline & Desafio & 10 & 2 & 5 & 1 & 1 & 4 & 1 & & 2 & 26 \\
\hline & Emoção & & 5 & 1 & & & & & & & 6 \\
\hline & Adrenalina & & 1 & & & & & & & & 1 \\
\hline & Extremo & & & & & & & 1 & & & 1 \\
\hline & Total & 14 & 33 & 7 & 2 & 3 & 11 & 3 & 2 & 2 & 77 \\
\hline \multicolumn{2}{|c|}{ Total } & 64 & 59 & 41 & 27 & 21 & 17 & 15 & 8 & 7 & 259 \\
\hline
\end{tabular}

O glossário do risco como perigo foi pouco usado ( $\mathrm{N}=54$ ), com exceção da palavra "perigo" que apareceu em 30 matérias nas mais diversas áreas. A freqüência de uso é um pouco maior nas temáticas Política, Ambiente e Saúde. É exemplo de uso na Política a matéria "Sangue no Báltico", publicada na Veja de 23/1/1991 (seção "Internacional") que tinha por chamada: "Gorbachev manda tanques para a Lituânia, promove o maior massacre da Perestroika e assusta o mundo com o perigo da volta à ditadura" (p. 58). A matéria "Plantas em perigo", que abordava o comércio ilegal de plantas raras (Veja, 16/7/1975, p.76) e ilustra o uso do glossário na área ambiental.

O glossário associado ao risco-probabilidade foi utilizado, sobretudo, nas temáticas Política, Economia, Lazer, Saúde e Tecnologia. Em todas essas áreas, com exceção de Lazer, a abordagem da análise dos riscos, própria do risco como probabilidade, já está bastante consolidada. Não surpreende, portanto, a migração dessa vertente da linguagem dos riscos de áreas especializadas para discursos voltados ao público leigo. São duas as palavras mais freqüentes: risco $(\mathrm{N}=80)$ e os derivativos de segur* (segurança, seguros, $\mathrm{N}=33$ ). Risco é o glossário preferido nas áreas da Economia e Saúde. Na Tecnologia, risco e segurança têm freqüência de uso semelhante; já na Política e Lazer, o risco tende a estar associado à questão da segurança.

A matéria de capa da Veja de 16/9/1987, intitulada "Riscos da gravidez: $\mathrm{O}$ medo de ter bebês que nascem com defeitos" é exemplo de uso do glossário na área da Saúde. Na seção Economia da Veja de 23/1/91, na matéria "Filés do Mercado" há referência à "estratégia semelhante para diminuir o risco dos créditos para o Brasil" (p. 70). E na seção "Divertimento", área de Lazer da Veja de 22/1/1997, na matéria intitulada "Ases-mirins", com o subtítulo "Crianças que enfrentam o risco em pistas de moto-cross", abordava-se uma nova modalidade de atividade, o minicross. Acompanhava o texto uma foto do pequeno campeão mineiro: um garoto de 8 anos.

Já o glossário do risco-aventura, com 77 ocorrências, foi usado, sobretudo, na área de Lazer ( $\mathrm{N}=33$ ocorrências), na Política $(\mathrm{N}=14)$ e Esportes $(\mathrm{N}=11)$. As duas palavras mais freqüentes foram "aventura" e "desafio", sendo a primeira mais usada na área de Lazer e a segunda, na Política.

A título de exemplo, vale contrastar o uso da palavra "aventura" na área do lazer em dois momentos distintos: em 1970 e 2002. Na Veja de 17/6/1970, na seção "Vida moderna" (p. 60), na matéria intitulada "A aventura sem riscos", falava-se sobre a diminuição dos riscos em safáris africanos. Tratava-se, portanto, de um programa turístico e a foto que acompanhava o texto era a de um café da manhã repleto de comida tipicamente nor te-americana. Já a Veja, de 18/12/2002, na seção "Guia", trazia matéria sobre "Peruas na lama", referindo-se aos carros 4x4, especiais "para aqueles que gostam de aventura em qualquer tipo de terreno" (p. 140).

Os desafios políticos se referem às imponderabilidades vivenciadas por países onde há conflitos ou mudanças de orientação político-econômica. Por exemplo, na Veja de 21/ 4/1976 foi veiculada uma matéria intitulada "Israel: De- 
safio árabe" (p. 41). Sete anos depois, na Veja de 26/1/83 (p. 50) o foco era os efeitos da crise econômica. A matéria tinha por título "Para salvar o mundo - A crise econômica põe em jogo a sobrevivência das sociedades livres" e por subtítulo, "Os desafios dos EUA". No texto, era abordada a responsabilidade dos EUA para a rápida recuperação econômica, defendendo o livre mercado. Mais recente, a matéria da Veja de 14/3/2002 tinha por foco a China que "anunciava investimentos para acelerar a expansão econômica e encarar o desafio de abrir seu mercado de 1,3 bilhão de pessoas" (p. 54).

A Política foi a única área que fez uso freqüente dos glossários das três tradições. Deduz-se que a linguagem política é bastante polissêmica.
As Especificidades do Uso do Glossário do Risco em Revistas para Públicos Distintos: A Análise Sincrônica

A Veja é uma revista de informação semanal destinada aos públicos A e B. A análise sincrônica das 101 revistas compradas em banca no mês de outubro de 2003 complementa a análise no tempo e possibilita entender o riscoaventura na perspectiva dos públicos específicos a quem se destinam essas revistas. Em seis das 15 temáticas de revistas da amostra, o glossário do risco, em qualquer das três tradições, não foi encontrado: Adolescentes, Alimentos, Bebidas e Gastronomia; Arte, Cultura e Música; Eletrônica, Ótica e Mecânica; Engenharia, Arquitetura e Construção e Saúde, Beleza e Moda. Para as demais, como ocorreu na Veja, o glossário mais utilizado foi o do risco-probabilidade $(\mathrm{N}=55)$, seguido pelo do risco-aventura $(\mathrm{N}=33)$.

Tabela 2

Análise Sincrônica do Glossário do Risco-Perigo em Matérias por Temática das Revistas

\begin{tabular}{lccccc}
\hline Temáticas & Perigo & Sorte & Ameaça & Azar & Total \\
\cline { 2 - 6 } & & & & & \\
Esportes, Turismo & 2 & 1 & 1 & 1 & 5 \\
Feminina Ambiente & 1 & 2 & & & 3 \\
Economia e Administração & 1 & & 1 & & 2 \\
Infanto Juvenil & 1 & & 1 & 2 \\
Automobilismo e transporte & 1 & & & 1 \\
Agropecuária & 1 & & & 1 \\
Masculina & 7 & 4 & 3 & 1 & 1 \\
Total Geral & & & & 1 \\
\hline
\end{tabular}

O glossário do risco-perigo (Tabela 2) foi utilizado em 15 matérias, sendo "perigo" a palavra mais freqüente, encontrada, por exemplo, nas revistas voltadas a Esporte, Turismo e Meio Ambiente. Na revista Náutica, na seção "Por to Livre" (N. 182, 2003), foi publicada matéria intitulada "Perigo que se arrasta", com o seguinte subtítulo: "Ignorar as armadilhas do mar é como ter os pés firmes no ar! Distração e inexperiência podem acabar no fundo, no fundo, do fundo... do mar" (p. 162). No Índice da revista Mergulho, havia uma citação do fotógrafo Carlos Cocchin, responsável pela matéria desenvolvida na página 187, a respeito do arquipélago das Cagarras no Rio de Janeiro:

Preocupado com a ameaça de a cidade do Rio de Janeiro perder um valioso tesouro, decidi trazer do fundo do mar tantas imagens quanto ... É a minha contribuição para alertar o público sobre o perigo de desaparecimento irreversível da maioria das espécies documentadas no local. (Mergulho, outubro 2003, p. 5).

Tabela 3

Análise Sincrônica do Glossário do Risco-Probabilidade em Matérias por Temática das Revistas

\begin{tabular}{|c|c|c|c|c|c|c|c|c|}
\hline Temáticas & Risco & $\begin{array}{l}\text { Proteção/ } \\
\text { Preservação }\end{array}$ & Chance & Segur* & Alerta & Aposta & Jogo & Total \\
\hline Informação semanal & 14 & & 3 & 1 & & 1 & 1 & 20 \\
\hline Feminina & 8 & & 1 & & 1 & & & 10 \\
\hline Economia e Administração & 5 & 1 & & 1 & 2 & 1 & & 10 \\
\hline Informática / Games & & 2 & 1 & 1 & & & 1 & 5 \\
\hline Esportes, Turismo Meio Ambiente & 1 & 2 & & & & & & 3 \\
\hline Automobilismo e transporte & 1 & & & 2 & & & & 3 \\
\hline Infanto Juvenil & 1 & & & & & & & 1 \\
\hline Agropecuária & 1 & & & & & & & 1 \\
\hline Interesse Geral e Atualidades & & 1 & & & & & & 1 \\
\hline Edições de Aniversário & 1 & & & & & & & 1 \\
\hline Total Geral & 32 & 6 & 5 & 5 & 3 & 2 & 2 & 55 \\
\hline
\end{tabular}


As palavras do glossário do Risco-probabilidade (Tabela 3) foram encontradas principalmente nas revistas de Informação Semanal ( $\mathrm{N}=2 \mathrm{O})$, aquelas relacionadas com Economia e Administração $(\mathrm{N}=10)$ e nas Femininas $(\mathrm{N}=10)$. A palavra mais utilizada foi "risco", correspondendo a $58 \%$ das ocorrências deste glossário. Assim, na seção "Saúde e Fitness" da revista Época (No 284, out. 2003), em matéria sobre os avanços nas análises morfológicas, intitulada "Chances reais", afirmava-se, no subtítulo: "Avanço: Análise reduz risco de gravidez múltipla” (p. 104). Na revista

Tabela 4

Análise Sincrônica do Glossário do Risco-Aventura em Matérias por Temática das Revistas

\begin{tabular}{|c|c|c|c|c|c|c|c|}
\hline Temáticas & Desafio & Aventura & $\begin{array}{l}\text { Radical + } \\
\text { corridas } \\
\text { alucinadas }\end{array}$ & $\begin{array}{l}\text { Encarar } \\
\text { enfrentar }\end{array}$ & Adrenalina & Limite & Total \\
\hline Esportes, Turismo Meio Ambiente & 1 & 8 & & 2 & & 1 & 12 \\
\hline Feminina & 3 & 1 & 1 & 1 & 1 & & 7 \\
\hline Automobilismo e transporte & 3 & & 1 & & & & 4 \\
\hline Economia e Administração & 3 & & & & & & 3 \\
\hline Agropecuária & 2 & & & & & & 2 \\
\hline Informação semanal & & & & & 1 & & 1 \\
\hline Informática / Games & & & 1 & & & & 1 \\
\hline Infanto Juvenil & & & & 1 & & & 1 \\
\hline Interesse Geral e Atualidades & & & 1 & & & & 1 \\
\hline Edições de Aniversário & & & 1 & & & & 1 \\
\hline Total Geral & 12 & 9 & 5 & 4 & 2 & 1 & 33 \\
\hline
\end{tabular}

A palavra "desafio", com 12 ocorrências, foi usada em uma grande variedade de revistas e temáticas: Agropecuária, Automobilismo e Transporte, Economia e Administração, Esportes, Turismo e Meio Ambiente, assim como em revistas voltadas ao público feminino. Como exemplos de uso, selecionamos as ocorrências encontradas na revista Pequenas Empresas Grandes Negócios, PEGN (área temática da Economia e Administração) e $U M A$ (populações específicas, revistas femininas).

Na PEGN (No 177, 2003) há três ocorrências de uso dessa palavra. A seção "Do Editor" (p. 5 ) tinha por título: "Desafio permanente", referindo-se à matéria de capa intitulada "O poder da diferença: Como se destacar no mundo dos negócios e sair na frente da concorrência”. A matéria localizada na página 38 , intitulada "O negócio familiar tem futuro", trazia como destaque a seguinte asseveração: "Nesta entrevista, Gentil (referindo-se ao entrevistado Eduardo Gentil) fala dos desafios das empresas familiares, que representam $70 \%$ de todas as empresas do mundo, e diz o que as famílias podem fazer desde já para que seus negócios sobrevivam por gerações”. E na seção "Consumo", afirmava-se que "O desafio é fazer do ponto-devenda um teatro e de cada cliente um ator" (p. 44).

Na $U M A$ (No 37, 2003), edição comemorativa do terceiro ano da revista, a tônica, em duas matérias, era o desafio. Na primeira, intitulada "Que deusa é você", as autoras (Izabel Christina e Regina Valladares) faziam o convite
Isto É, na seção "Educação e Cidadania", a personagem em destaque foi denominada de "Porta voz da paz" (p. 52). A matéria tinha por subtítulo: "Diane Tillman viaja pelo mundo para divulgar programas que recuperam crianças em situação de risco".

Em contraste, o glossário do risco-aventura (Tabela 4) teve um maior número de ocorrências nas revistas voltadas a Esporte, Turismo e Meio Ambiente (N=12), aparecendo, também, naquelas voltadas ao público feminino $(\mathrm{N}=7)$. A palavra mais usada foi "desafio" $(\mathrm{N}=12)$, seguida de "aventura" ( $\mathrm{N}=9)$. para descobrir que deusa rege nossas atitudes. "A sexy Afrodite, a aventureira Artemis, a sábia Atena... Em cada uma de nós, todas as deusas convivem. Mas uma delas é sua alma, a representante dos seus anseios e desafios. Descubra quem rege suas atitudes." (p. 60). O convite era acompanhado de um teste, no qual cada letra equivalia a uma das seis deusas apresentadas na matéria. Tendo identificado sua deusa, a leitora era remetida ao texto que situava suas principais características e desafios. Tratava-se, portanto, de convite ao autoconhecimento.

Também a matéria intitulada "Inteligência emocional no trabalho" (p. 78-81), convidava ao autoconhecimento, desta vez para auxiliar o sucesso na vida profissional. No texto, a autora, Daniela Salú, listava os dez mandamentos para colocar as características femininas a favor do sucesso. Dos dez, os dois primeiros usavam a linguagem dos riscos: "Encarar tarefas difíceis como desafios" e "Assumir riscos para buscar soluções originais". Ambos aludiam à "ousadia" que pode levar a soluções originais, termo relacionado ao glossário de risco como aventura.

\section{Discussão: Contrastando “Tempos” e "Públicos”}

As revistas, como afirma Marília Scalzo (2004), têm como principal característica o endereçamento para públicos claramente definidos pela segmentação por gênero, idade ou interesses e estilos de vida. Diz Scalzo que "É na 
revista segmentada, geralmente mensal, que de fato se conhece cada leitor, sabe-se exatamente com quem se está falando" (p. 15).

Essa sintonia com seu público, e conseqüentemente com o tempo e lugar em vivem seus leitores, faz das revistas fontes ricas para historiadores e estudiosos dos processos de produção de sentidos. Tomadas em uma perspectiva temporal, como fizemos na análise da revista Veja, permitem entender "os hábitos, as modas, os personagens de cada período, os assuntos que mobilizam grupos de pessoas" (Scalzo, 2004, p. 16). Tomadas na perspectiva da segmentação do público, possibilitam entender esses hábitos, modas e assuntos situados em estilos de vida. As revistas, portanto, podem ser entendidas como linguagens sociais que, por terem endereçamentos singulares, seguindo as teorizações de Bakhtin (1994), se constituem também como gêneros de fala.

Interessava-nos, nesta pesquisa, entender as especificidades da linguagem dos riscos na mídia (Spink \& Menegon, 2004), considerando, sobretudo, os repertórios sobre risco assim circulados e tornados disponíveis para dar sentido aos eventos arriscados de nosso cotidiano. Buscávamos, ainda, compreender os usos do glossário do risco nas diferentes tradições propostas por Spink (2001) e, especialmente, a emergência da tradição do risco-aventura, considerada pela autora como fenômeno associado às características da modernidade tardia.

A análise "no tempo" sugere que os glossários da tradição risco-perigo e risco-probabilidade já estão bastante consolidados e que seu uso traz ressonâncias dos contextos históricos em que essas tradições tomaram forma. As referências a perigos e ameaças estão mais presentes em contextos nos quais os riscos são imponderáveis e em cujo controle temos pouco poder. Lembramos, assim, que, na revista Veja, esses glossários foram utilizados especialmente na Política e em matérias sobre o Ambiente. Já as referências a risco, e seu "outro", a segurança, se fez presente nas áreas temáticas em que o conceito já está consolidado: a Economia, a Tecnologia e a Saúde.

É no enquadre do risco-aventura que vemos surgir novos vocábulos para se referirem às emoções despertadas pelos esportes radicais ou para posicionar aqueles que optam por correr risco. Dois vocábulos têm destaque: a aventura, que se fez presente, sobretudo, para falar de novas modalidades de esportes de ação, e o desafio que, na Política, dá as conotações da pessoalidade em uma formação social marcada por processos de individualização.

Cabe aqui um pequeno desvio de percurso, com a intenção de problematizar a questão da temporalidade. A revista Veja, criada em 1968, tinha 35 anos de existência, quando esta pesquisa foi realizada. Se, de um lado, considerarmos o tempo longo das tradições discursivas sobre o risco, nosso tempo de análise parece assaz precário. Por outro lado, porém, não se trata de fazer uma história dessas práticas discursivas; nosso objetivo era entender as novas configurações de sentido com base na intersecção entre nossa história vivida e as maneiras de incorporar o novo nessas histórias. Assim, qualquer ano de publicação da revista Veja carrega consigo os anos antecedentes e suas repercussões. Realizar uma análise temporal, qualquer que seja sua duração, é construir a história. Segundo Jenkins (2001), o presente precisa do passado, a fim de se localizar e se legitimar, podendo dessa maneira, vislumbrar o futuro. O passado só existe agora, no momento em que dirigimos um olhar para o discurso vigente em épocas anteriores. É aí que o passado se transforma em história, quando é ressignificado por nosso olhar para trás dos ombros. "Assim como somos produtos do passado, assim também o passado conhecido (a história) é um artefato nosso" (2001, p. 33).

A história das práticas discursivas sobre risco pode ser traçada a partir de qualquer marco zero: a elaboração da teoria da probabilidade; os esforços de sistematização de dados sobre populações; o nascimento da Epidemiologia; as análises de risco consolidadas após a Segunda Guerra Mundial; a inclusão dos esportes radicais na indústria de seguros; ou ainda, a crescente tendência a politizar o risco por meio do discurso sobre vulnerabilidade. São muitas as versões dessa história e a nossa, singela, voltase ao uso desses discursos para criar e legitimar certas posições de pessoa, compatíveis com esses tempos hipermodernos.

Esses posicionamentos são mais bem apreendidos no fluxo da comunicação em que o público tem cara: as revistas segmentadas. Assim, na Veja, na Isto É ou Exame, enfim, nas revistas de interesse geral e informação semanal, um leque de assuntos é oferecido aos leitores, cada qual reproduzindo seus laços com determinados domínios de saber. Não surpreende, portanto, que seja nas revistas voltadas ao Esporte, Turismo e Meio Ambiente que encontramos um uso mais dinâmico do glossário do risco-aventura, recheado de menções à aventura, aos limites, aos desafios e à experiência da adrenalina.

Como ilustração das sensibilidades assim legitimadas, encerramos esta reflexão com o texto de anúncio da Smolder, loja de acessórios e camisetas, veiculado na revista Fluir (Ano 19, No 216, 2003, p. 125). O anúncio tem por foco, em fundo amarelo (como a areia da praia), a foto do surfista Aldemir Calunga em manobra em tubo de onda gigante. Embaixo da imagem, a mensagem publicitária: "O tempo pára dentro de um tubo. O corpo ferve. A vida passa decidida no mar. For extreme adventures". Não importa que a aventura extrema seja a do outro (o surfista) e ao leitor-consumidor caiba apenas o uso de acessórios que o identifiquem com uma dada comunidade de consumo; a possibilidade do risco-aventura e a promessa da emoção a ele associada passaram a fazer parte do imaginário social.

\section{Referências}

Adam, B., \& Van Loon, J. (2000). Introduction: Repositioning risk: The challenge for social theory. In B. Adam, U. Beck \& J. Van Loon (Eds.), The risk society and beyond (pp. 1-31). London: Sage.

Anuário de Mídia - Revistas. (2002). São Paulo, SP: Meio e Mensagem. 
Bakhtin, M. (1994). The problem of speech genres. In C. Emerson \& M. Holquist (Eds.), Speech genres and other late essays (pp. 60-102). Austin, TX: University of Texas Press.

Bakhtin, M. (1995). Marxismo e filosofia da linguagem. São Paulo, SP: Hucitec

Beck, U. (1992). Risk society: Towards a new modernity. London: Sage.

Douglas, M. (1992). Risk and blame. London: Routledge.

Editora Abril. (2000). A revista no Brasil. São Paulo, SP: Autor.

Faïta, D. (1997). A noção de "gênero discursivo" em Bakhtin: Uma mudança de paradigma. In B. Brait (Ed.), Bakhtin, dialogismo e construção de sentido (pp. 159-177). Campinas, SP: Editora da Universidade de Campinas.

Foucault, M. (1995). Microfísica do poder. Rio de Janeiro, RJ: Graal.

Jenkins, K. (2001). A história repensada. São Paulo, SP: Contexto.

Lupton, D. (1999). Risk. London: Routledge.

Machlis, G. E., \& Rosa, E. A (1990). Desired risk: Broadening the social amplification risk framework. Risk Analysis, 10, 161-168

Renn, O. (1992). Concepts of risk: A classification. In S. Krimsky \& D. Golding (Eds.), Social theories of risk (pp. 53-79). Westport, CT: Praeger.

Scalzo, M. (2004). Jornalismo de revista. São Paulo, SP: Contexto

Spink, M. J. (2000a). Risco e educação em saúde: Das perspectivas individuais à sensibilidade ao contexto cultural. In M. J. Spink (Ed.), A construção social do risco no cenário da Aids (Relatório de Projeto Integrado). Brasília, DF: CNPq.

Spink, M. J. (200ob). Contornos do risco na modernidade reflexiva: Contribuições da Psicologia Social. Psicologia \& Sociedade, 12, 156-173.

Spink, M. J. (2001). Trópicos do discurso sobre o risco: Riscoaventura como metáfora na modernidade tardia. Cadernos de Saúde Pública, 17, 1277-1311

Spink, M. J., Medrado, B., \& Mello, R. P. (2002). Perigo, probabilidade e oportunidade: A linguagem dos riscos na mídia. Psicologia, Reflexão e Crítica, 15, 151-164.

Spink, M. J. P., \& Menegon, V. M. (2004). Práticas discursivas como estratégias de governamentalidade: A linguagem dos riscos em documentos de domínio público. In L. Iñiguez (Ed.), Manual de Análise do Discurso em Ciências Sociais (pp. 258311). Petrópolis, R.J.: Vozes. 